\title{
MÚSICA, ARTE Y CEREMONIAL EN LAS REALES HONRAS FÚNEBRES DE FERNANDO VII CELEBRADAS EN MADRID (1834)
}

\author{
POR \\ MARÍA ORDIÑANA GIL ${ }^{1}$ \\ Universidad Internacional de Valencia
}

\section{RESUMEN}

A través del estudio de las exequias por Fernando VII celebradas en Madrid y la descripción de sus manifestaciones artísticas se pretende investigar la función de la música en las ceremonias de reales honras fúnebres españolas, así como la coherencia de sus significados con los programas iconográficos configurados en el aparato funeral.

PALABRAS CLAVE: exequias reales; honras fúnebres; Fernando VII; aparato funeral; túmulo; Francisco Andreví; misa de difuntos; oficio de difuntos.

\section{MUSIC, ART AND CEREMONIAL IN THE FUNERAL COMMEMORATION FOR FERDINAND VII CELEBRATED IN MADRID (1834)}

\author{
ABSTRACT \\ office for the dead. \\ $\begin{array}{ll}\text { Recibido/Received } & \text { 15-05-2019 } \\ \text { Aceptado/Accepted } & \text { 08-01-2020 }\end{array}$
}

Through the study of the funeral of Ferdinand VII celebrated in Madrid and its artistic manifestations, this article seeks to investigate the function of music in the ceremonies of Spanish royal funeral honors, as well as the degree of coherence within the iconographic programs configured in the funeral apparatus.

KEY WORDS: royal obsequies; funeral ceremonies; Ferdinand VII; funeral apparatus; catafalque; Francisco Andreví; requiem mass;

Cómo CITAR ESTE ARTículo / CITATION: Ordiñana Gil, María. 2020. «Música, arte y ceremonial en las reales honras fúnebres de Fernando VII celebradas en Madrid (1834)». Hispania Sacra LXXII, 146: 539-549. https://doi.org/10.3989/hs.2020.040

\section{INTRODUCCIÓN}

Las capillas musicales fueron prácticamente hasta el siglo XIX algunos de los centros más importantes de formación estética para los fieles. Los asistentes a la liturgia gozaban y participaban de unos actos celebrados con todo esplendor que exigían una educación cultural y artística. ${ }^{2}$ Los músicos, vinculados a los estamentos religiosos, procuraban ofrecer cierta educación musical desde cada una las capillas de las catedrales e iglesias de las diferentes ciudades españolas. ${ }^{3}$

1 mordinana@universidadviu.com /

ORCID iD: https://orcid.org/0000-0001-9606-3572

2 Virgili Blanquet 1995

3 Para un estado de la cuestión de la música religiosa en el siglo XIX español, véase Virgili Blanquet 2004.
Una de las capillas que ha ofrecido mayor altura musical a lo largo de los tiempos, y que ha estado sometida a los cambios producidos por las circunstancias políticas y sociales, es la Capilla Real. Su proceso de consolidación ha estado ligado a los enlaces reales y su herencia por parte de las diferentes dinastías que se han sucedido. ${ }^{4} \mathrm{Si}$ bien su existencia era obligada por etiqueta palatina y simbología de poder, su composición y recursos han dependido en gran medida de la voluntad de los monarcas, así como de su afición y gusto musical.

La Capilla Real era la encargada de oficiar los actos religiosos de los monarcas y sus familias. De entre las celebraciones litúrgicas en las que la música era considerada un elemento necesario y obligatorio, destaca la ceremonia de las exequias

\footnotetext{
4 Robledo Estaire 1999.
} 
reales u honras fúnebres. Tras la muerte del rey se iniciaban una serie de actos considerados los más significativos del protocolo ceremonial funerario de la monarquía hispánica. ${ }^{5}$ Eran celebraciones con un alto grado de magnificencia a las que contribuía mayormente la interpretación de una música compuesta ex profeso. El entonces maestro de la Capilla Real era el encargado de componer un oficio y misa de difuntos siguiendo la estructura del rito romano - estandarizada por los decretos tridentinos $-{ }^{6}$ y la tradición compositiva española. ${ }^{7}$

La celebración de la muerte regia ha despertado gran interés entre los historiadores e historiadores de Arte, especialmente centrado en el análisis de los túmulos. Esta línea de investigación iniciada por Maza (1946) experimentó una gran apertura a partir de los años sesenta con trabajos como los de Bonet Correa (1960 y 1961), Azcárate Ristori (1962) y Bottineau (1968) y prosiguiendo, hasta la actualidad, con publicaciones en torno al caso español e hispanoamericano. ${ }^{8}$ Si bien en estos estudios se han analizado en profundidad los programas iconográficos, se han obviado los significados provenientes de otras manifestaciones artísticas como la música. Ciertamente, la actividad musical que tenía lugar durante las exequias reales ha sido poco estudiada hasta fechas recientes. ${ }^{9}$ Las composiciones musicales interpretadas en estas ceremonias no han despertado el interés de los investigadores más allá de algunas ediciones críticas y discográficas. ${ }^{10}$ El motivo puede deberse a la escasa información que proveen las fuentes principales, como son los libros y expedientes de exequias, o tal vez a la dificultad en la reconstrucción de las músicas de las reales honras fúnebres debido al incendio del Real Alcázar de Madrid de 1734.

A pesar de la realidad histórica, una de las exequias reales más significativas en cuanto al despliegue de recursos y el cumplimiento de la etiqueta funeraria fue la celebrada por Fernando VII en Madrid. La organización y desarrollo de sus honras fúnebres mostró el esfuerzo realizado por el monarca en el mantenimiento del culto divino con el boato de épocas anteriores. Se sabe que durante el reinado de Fernando VII se iniciaron diversas reformas en la Capilla Real que permitieron acercarla nuevamente a la actividad monárquica y eclesiástica - pasando a depender económica y administrativamente de la Real Casa - y mantener una numerosa orquesta y coro muy similar a la de finales del siglo XVIII. ${ }^{11}$ Gracias a la dotación y estructura trazada por Fernando VII, así como a su empeño en la conservación de la etiqueta funeraria, fue posible la construcción de un completo aparato funeral y la composición e interpretación de un oficio y

\footnotetext{
5 Varela 1990.

6 Caeremoniale Episcoporum iussu Clementis VIII. Pontificis Maximi novissime reformatum. Omnibus ecclesiis, paecipue autem Metropolitanis, Cathedralibus \& Collegiatis per utili, ac necessarium. Venetiis Ex Typographia Nicolai Misserini, Anno lubilar MDC, Mense Septembris.

7 En Ordiñana Gil 2016 se incluye un estudio de la tradición de la música para exequias reales en España desde el siglo XVII hasta el XIX.

8 En este punto no es nuestro objeto citar todos los trabajos en torno a esta línea de investigación, pero sí destacar los autores Mejías Álvarez 2002; Allo Manero y Esteban Lorente 2004 y Soto Caba 1988 para el ámbito español y para el americano Ramos Sosa 1992; Morales Folguera 1988; Berlin y Luján Muñoz 1983; Campos y Fernández de Sevilla 2001 y Rodríguez Moya y Mínguez Cornelles 2012.

9 Fuente Charfolé 2013; Flores Rodrigo 2005; González Marín 2004b.

10 Iglesias 1989; Lolo 2000; Gil Tárrega 2001; González Marín 2004a; Garrido 1998; Garrido y Zaldívar Gracia 2008.

11 Lolo 1995.
}

misa de difuntos. En suma, se produciría una auténtica unión de las artes cuyo objetivo era el de conmocionar los sentidos desde su comienzo más inmediato: la muerte del soberano.

\section{MUERTE DEL REY Y TRATAMIENTO DEL CUERPO}

El domingo 29 de septiembre de 1833 moría súbitamente el rey Fernando VII dejando el trono a su hija Isabel II. El oficio de la defunción puede leerse en la publicación extraordinaria de la Gaceta de Madrid del mismo día: «a las tres menos cuarto sobrevino al Rey repentinamente un ataque de apoplejía tan violento y fulminante que, a los cinco minutos, sobre poco más o menos, terminó su preciosa existencia. Dios guarde a V[uestra] E[excelencia] muchos años. Palacio 29 de septiembre de $1833 » .{ }^{12}$

Como es sabido, María Cristina de Borbón ejerció de reina gobernadora regente durante la minoría de edad de su hija. Inmediatamente después de la muerte del monarca se encargó de imponer un luto general suspendiendo todos los espectáculos y diversiones públicas: «S[u] M[ajestad] la Reina Gobernadora de estos reinos, en nombre de su Augusta Hija la Reina Doña ISABEL II, ha mandado vestir lutos generales por seis meses, contados desde el día 29 de setiembre por la muerte del S[eño]r D[on] FERNANDO VII (que en gloria está)». ${ }^{13}$

Tal como era costumbre, en los días posteriores se llevó a cabo la primera fase del protocolo ceremonial funerario configurado por los actos relacionados con el tratamiento del cuerpo: exposición, traslado y entierro. Todas las revistas y periódicos del momento recogían los acontecimientos de esta ceremonia privada considerada de interés nacional. El 4 de octubre, La Revista Española narraba los pormenores del real entierro:

Muerto el Rey D[on] Fernando (que en gloria está) [...] la Augusta Viuda, en medio del inagotable dolor que la oprimía, pidió que no se removiera el real cadáver hasta que hubiese transcurrido 48 horas, por lo mismo que la muerte había sido tan repentina e inesperada. Mas no pudiendo cumplírsele este tierno y piadoso deseo, por haber declarado los facultativos en la mañana del día 30 que no convenía esperar más; [...] vestido el real cadáver con el uniforme de gran gala de capitán general [...] se le condecoró con todas las insignias de collares, grandes cruces, así nacionales como extranjeras que $\mathrm{S}[\mathrm{u}]$ M[ajestad] usaba, y se le depositó en el féretro dejando este destapado por la parte superior, y cubriendo la inferior con los mantos de las reales órdenes. ${ }^{14}$

El alto grado de detalle de las descripciones no solo se debía al supuesto interés del pueblo, también revelaba todo aquello que no formaba parte de la etiqueta funeraria al uso y que humanizaba de algún modo a la realeza. Este fue el caso del deseo de la reina María Cristina de Borbón por conservar un mechón de su difunto esposo.

Poco antes de cerrarse el féretro del amado Monarca, cuya pérdida lloramos, recogió el Exc[elentísi] mo S[eñor]r Duque de Hijar, Sumillar de Corps de S[u] M[ajestad], y remitió a la REINA Gobernadora el cabello del Augusto difunto. Hemos sabido que en ello no ha

12 Gaceta de Madrid Núm.119, 1. 29-IX-1833.

13 La Revista Española Núm. 99, 7. 1-X-1833.

14 La Revista Española Núm. 100, 11. 4-X-1833. 
hecho mas que cumplir $\mathrm{S}[\mathrm{u}] \mathrm{E}$ [xcelencia] con un encargo especial de la virtuosa y desconsolada CRISTINA, quien había pedido encarecidamente aquella prenda, en memoria, sin duda, del tierno cariño que la profesaba su amante Esposo [...] el Padre de sus idolatradas hijas. ${ }^{15}$

Concluido el tratamiento del cuerpo del monarca, el féretro fue entregado formalmente al Mayordomo Mayor y conducido al gran salón de Embajadores para su exposición. Tras dicho acto y siguiendo la etiqueta, el Mayordomo Mayor hizo formal entrega del cadáver a la guardia de los Monteros de Espinosa quienes debían custodiarlo y trasladarlo posteriormente al Monasterio de San Lorenzo de El Escorial.

El 3 de octubre, dispuesta la traslación del cadáver al monasterio, se inició la procesión de la corte con «timbales y trompetas de la Real caballeriza, con sordinas» ${ }^{16}$ y acompañados por «Doce capellanes de honor a caballo, con la música y dependientes de la Real Capilla, todos con hachas encendidas $"{ }^{17}$ En este punto cabe destacar que el sepelio de Fernando VII fue caracterizado por la magnificencia de otras épocas. Ante la larga procesión hacia El Escorial un periodista confundido entre los espectadores expuso: "Un temor religioso ocupaba los corazones de todos, que se hablaban en baja y susurrante voz como si hubiera temido aún a tan larga distancia perturbar el descanso del llorado Monarca: parecía que cada cual sentía toda la grandeza y sublimidad del cuadro que presenta un pueblo vivo que va a ver pasar un rey muerto». ${ }^{18}$

Al llegar al monasterio, el Real cuerpo fue recibido por el abad mitrado, el diácono, subdiácono y toda la comunidad del monasterio. Tras la lectura de los decretos acostumbrados y la notificación de la muerte del Rey, la Real Capilla ${ }^{19}$ entonó un último responso, el salmo Si iniquitates y un Miserere a 4, este último en la entrada al patio de los Reyes. Colocado el féretro en la iglesia de El Escorial, la Real Capilla y la propia del monasterio subieron al coro y dieron principio al invitatorio y lecciones compuestas por el insigne padre Soler ${ }^{20}$ y los maitines. Finalmente, se procedió a la sepultura del monarca siguiendo rigurosamente el protocolo. La citada revista concluye estos primeros actos inmediatos a la muerte del Rey con las siguientes apreciaciones:

Nada más tristemente magnífico, nada más sublime y que más efecto produzca en el corazón del espectador en el momento de recordar que unos cuantos palmos de tierra van a encerrar para siempre muerto al que vivo la dominó, que el eco fúnebre y retumbante del cañón: su estruendo profundo se reproduce y contrasta sordamente en los inmensos patios del grandioso edificio:

15 La Revista Española Núm. 100, 11. 4-X-1833.

16 La Revista Española Núm. 102, 18. 8-X-1833.

17 La Revista Española Núm. 102, 19. 8-X-1833.

18 La Revista Española Núm. 102, 19. 8-X-1833.

19 En este punto, cabe considerar que desde la llegada definitiva de Fernando VII a la corte (1813) la Real Capilla sufrió modificaciones y revisiones al menos en tres ocasiones $(1815,1820$ y 1824) dotándola de un mayor número de intérpretes. Tal como señala Lolo (1995), e monarca pretendía recuperar la estructura de esta institución en los términos en los que se encontraba la primera vez que asumió el trono en 1808 y dejando atrás la situación de precariedad que la caracterizó durante el reinado de José I.

20 Se refiere a Antonio Soler Ramos (1729-1783), organista y maestro de capilla del monasterio de El Escorial. Además de la actividad incesante en ámbitos diversos se encargó de la formación musical de los infantes Antonio y Gabriel, hijos de Carlos III (Capdepón Verdú 1999). conmoviendo la alta sierra de Guadarrama, fondo del tétrico cuadro que presenta el Monasterio, se prolonga a lo lejos como interminable trueno y resuena progresivamente hasta morir del todo de valle en valle y de eminencia en eminencia. Confesamos que su ruido resonó en nuestro corazón y quisieron abrirse paso por nuestros ojos esas lágrimas, que suelen formar, digámoslo así, en el alma misma del hombre, en las situaciones extraordinarias de la existencia, en las grandes solemnidades, en los momentos de entusiasmo o de asombro, en los incomprensibles y misteriosos ratos de languidez y melancolía, de que está salpicada la vida. Entonces más que nunca recordamos la nada del mundo, cuando consideramos que todo lo más a que puede alcanzar el hombre que más puede, es a hacer más pública su muerte, es a perpetuar en la misma grandiosidad de su sepulcro la inmensidad de la humana flaqueza. ${ }^{21}$

\section{Celebración de las exequias reales de Fernando VII en SAN ISIDRO EL REAL}

Las honras fúnebres o exequias constituían la fase más pública y litúrgica de las conmemoraciones por la muerte del monarca y se celebraban durante dos días consecutivos. Para tal ocasión, se desarrollaban todo tipo de manifestaciones artísticas: se construían aparatos funerales en el interior de las iglesias; se escribían sermones panegíricos y se componían e interpretaban cánticos, oficios y misas.

Tras la muerte de Fernando VII, debido a las circunstancias políticas, dicha ceremonia tomó un cariz más abierto al público general. Tanto fue así que la reina gobernadora María Cristina de Borbón resolvió que las exequias reales se celebraran en una de las iglesias con mayor cabida del momento: San Isidro el Real (Madrid). Según uno de los expedientes sobre la organización de las honras fúnebres que se conserva en el Palacio Real, el espacio destinado a tales actos fue determinado concretamente por «su capacidad, la espaciosa calle en que se halla situada, y las diversas entradas que tiene [las cuales] debían proporcionar un orden y comodidad que en vano se desearía en otro templo». ${ }^{22}$

FIGURA 1

Fachada de la iglesia San Isidro el Real (Madrid)

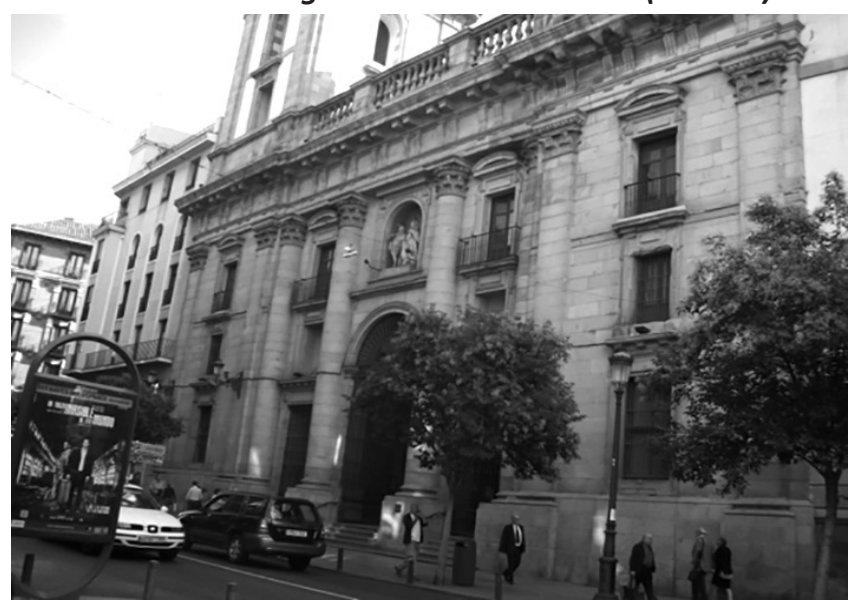

Fuente: fotografía de la autora.

21 La Revista Española Núm. 102, 19. 8-10-1833.

22 Organización de las honras del Señor Don Fernando VII, Archivo General de Palacio, Madrid (en adelante AGP), Sección Histórica, Caja 78, Expediente 7: 1 . 
La inclinación por un lugar de grandes dimensiones como la iglesia San Isidro está en línea con la tesis defendida por Varela según la cual, desde el reinado de Fernando VII, las exequias reales «dejan de ser una función cortesana para convertirse en otra pública». ${ }^{23}$ Es más, en las exequias de Fernando VII, según la documentación de Palacio, el número de asistentes superó las dos mil personas y para entrar al templo era necesaria una invitación impresa, como en cualquier otro acto social.

Las celebraciones tuvieron lugar los días 9 y 10 de mayo de 1834. El día 9, a las cuatro de la tarde, se celebraron las vísperas y nocturno de difuntos y el 10 , a las diez de la mañana, la misa de réquiem.

En cuanto a la organización de los asientos, se siguió una planificación minuciosa tal y como lo requería la etiqueta y la suntuosidad del acto. Sobre la organización de los invitados se conoce que:

Llegada la hora de las vísperas, ocuparon sus asientos en él las del evangelio los Exc[elentísi]mos S[eño]res Grandes de España cubiertos, a cuya cabeza se hallaba el Exc[elentísi]mo S[eñ]or marqués de Valverde, Mayordomo Mayor de S[u] M[ajestad] detrás de los Grandes estaban los Gentiles-hombres de la R[ea]I Casa y Boca. Al frente y las de la Epístola se había preparado para el Exc[elentísi]mo S[eñ]or embajador de Francia un taburete separado y reclinatorio según costumbre, y a su izquierda los mayordomos de semana de $\mathrm{S}[\mathrm{u}]$ M[ajestad]; y a la izquierda de estos, los capellanes de honor y predicadores de S[u] M[ajestad] todos individuos de precisa asistencia a la R[ea]l Capilla.

Las espaciosas tribunas del templo, se hallaban ocupadas por el Consejo de Gobierno, el de España e Indias, tribunales supremos, Jefes y Jefas de Palacio, S[us] S[eñorías] Secret[arios] del despacho, S[us] S[eñorías] del Cuerpo Diplomático, Capitán G[ene]ral y Gobernador.

A los dos costados del crucero de la iglesia detrás de los Grandes y mayordomos de semana, había dos estrados p[ar]a Grandes de España y clases distinguidas que se habían convidado.

El cuerpo de la iglesia fue ocupado por los títulos de Castilla, Gentiles-hombre de Cámara de S[u] M[ajestad] [,] Generales Jefes y oficiales de todas armas, autoridades eclesiásticas, militares y civiles, y demás caballeros de prim[er]a distinción.

A los costados y huecos de las capillas asistieron dos Religiosos de cada una de las comunidades de la corte: todo lo cual formaba el conjunto más lucia y respetuoso, ascendiendo el número de concurrentes a más de dos mil personas. ${ }^{24}$

Por último, en referencia a los celebrantes de las diversas misas, se sabe que el Arzobispo de Méjico, el obispo de Tortosa y el Patriarca de las Indias fueron los encargados de la celebración de las misas del Espíritu Santo, de la Virgen y de réquiem. Otros obispos que asistieron a las vísperas y responso fueron los obispo de Oaxaca (México) y Orihuela y los de Astorga y Canarias.

\section{EL APARATO FUNERAL}

Una de las contribuciones artísticas desarrolladas para honras fúnebres que ha sido más estudiada y valorada en el

\section{Varela 1990, 188.}

24 Organización de las honras del Señor Don Fernando VII, AGP, Sección Histórica, Caja 78, Expediente 7: 1-2. arte efímero español es el aparato funeral y, más concretamente, el túmulo funerario. Su grandiosidad, así como sus connotaciones simbólicas, lo han convertido en objeto de estudio por parte de la Historia del Arte. ${ }^{25}$

Para las honras de Fernando VII, la dirección en la ejecución del catafalco y la decoración del templo fue encargada a Francisco Javier de Mariátegui, Intendente honorario y Arquitecto Mayor de la Villa de Madrid. Según la descripción de la organización de las honras conservada en la sección Histórica del Archivo General de Palacio, se dictó:

Habiéndose resuelto S[u] M[ajestad] la Reina Gobernadora que se celebren solemnes y suntuosas exequias en sufragio del alma de su augusto y muy amado esposo, dignas de la alta persona a quien se dirigían y de quien se las dedicaba, se encargaron diseños del mausoleo que debía colocarse en el templo a los arquitectos mayores de Palacio y de la Villa de Madrid; y elegido por S[u] M[ajestad] el presentado por D[on] Fran[cis]co Xavier de Mariategui, Intenden[te] honorario y Arquitecto Mayor de la Villa, se encargó a este de orden de S[u] M[ajestad] la ejecución del catafalco y decoración del templo. ${ }^{26}$

Además del responsable del proyecto, para el desarrollo del aparato sería necesario el esfuerzo de diferentes personas y oficios. En este caso, los ayudantes del proyecto fueron el profesor Fernando Gutierrez y el delineante Mariano Peinao. La decoración (esculturas, bajo relieves, pintura, carpintería, dorados, tapicería, etc.) fue realizada, entre otros, por los profesores José Tomás y Geneves, José Piquer y Duart, José Ginés, Leonardo Alenza y Nieto, Francisco Martínez y Manuel Álvarez. ${ }^{27}$

\section{LA DECORACIÓN DEL TEMPLO}

El primer elemento a destacar del conjunto de la decoración realizada en la iglesia de San Isidro es el pórtico. La entrada al templo era uno de los elementos más vistosos del conjunto del aparato funerario, puesto que servía de soporte para anunciar la muerte del monarca. Para las exequias reales de Fernando VII consta que sus paredes y puertas interiores fueron revestidas con colgaduras negras $y$, en una de ellas, colocada una lápida coronada de laurel y sostenida por dos genios. En dicha lápida se inscribió el siguiente epitafio latino obra de Puyal, ${ }^{28}$ Rector del colegio: ${ }^{29}$

$\begin{array}{ll}\text { Ave Ferdinande Auguste } & \text { Salve, Fernando Augusto } \\ \text { Heic te Conjux Et Filia } & \text { aquí tu esposa y tu hija } \\ \text { Delicie Quondam tue } & \text { en otro tiempo tus delicias } \\ \text { Cum Sacrimis Parentant } & \text { con lágrimas te tributan honores fúnebres. }\end{array}$

Fuente: traducción propia.

25 Véase, entre otros: Allo Manero y Esteban Lorente 2004, Mejías Álvarez 2002 y Azanza López 2000.

26 Organización de las honras del Señor Don Fernando VII, AGP, Sección Histórica, Caja 78, Expediente 7: 1.

27 Descripción de la decoración realizada en la iglesia de San Isidro para las exequias de Fernando VII, AGP, Sección Histórica, Caja 78, Expediente 7.

28 Don Atanasio Puyal y Poveda (1751-1827) fue obispo de Caristo (auxiliar de Toledo) y de Calahorra. Cursó sus estudios en el Seminario de San Fulgencio de Murcia y con los Padres de la Compañía de Jesús. Opositó a la prebenda de San Isidro por imposición del Cardenal Lorenzana donde consta que obtuvo grandes éxitos como orador (Candel Crespo 1994).

29 Descripción de la decoración realizada en la iglesia de San Isidro para las exequias de Fernando VII, AGP, Sección Histórica, Caja 78, Expediente 7: 1. 


\section{FIgURA 2 \\ Fachada de la iglesia San Isidro el Real (Madrid) en la actualidad}

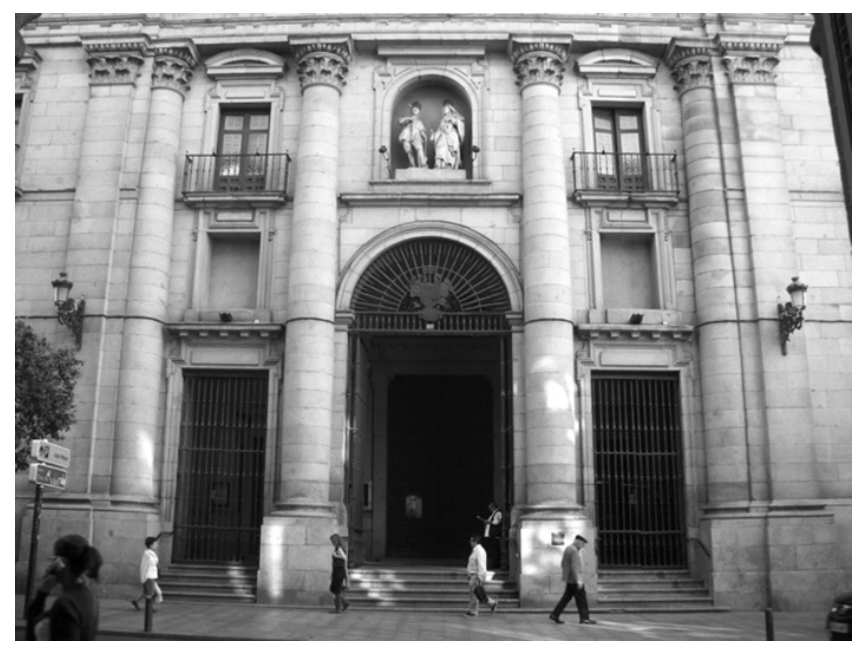

Fuente: fotografía de la autora.

Una vez dentro de la iglesia, el vestíbulo fue decorado con un bajo relieve en su cornisamento en el que se presentaban dos genios con los atributos análogos a la muerte del Rey. Sobre este pórtico, además, se construyó la tribuna para la orquesta que según la descripción era "obra indispensable por carecer este templo de coro, habiendo proporcionado su altura de modo que al mismo tiempo que la música obre todo el efecto apetecible, tenga el vestíbulo la Majestad y proporción que exigía el objeto». ${ }^{30}$

Siguiendo con la decoración de la iglesia, las naves centrales y el presbiterio se hallaban con colgaduras negras y decorados con candelabros. Las capillas, paredes y puertas también se habían enlutado a excepción de las pilastras, líneas de construcción y decoración arquitectónica: «la bóveda inclusa las pechinas, cuerpo de luces, media naranja y linterna presenta los mismos fondos que las paredes de la Iglesia, por manera que a pesar de estar toda enlutada se perciben con la mayor distinción las pilastras, fajas, resaltos y lunetos, lográndose al mismo tiempo contraponer al color general negro los necesarios puntos blancos, para que no hiciera pesado y monstruo». ${ }^{31}$

Con estas líneas puede advertirse la búsqueda del contraste de colores, negro y blanco, así como el cuidado en la exposición de los perfiles arquitectónicos. En este sentido, para resaltar todavía más este efecto se sabe que antes de las exequias reales la iglesia fue blanqueada, incluyendo la media naranja y la linterna. Así pues, el interior de la iglesia sigue vistiendo de negro, de acuerdo con la tradición, pero con discreción. Se cree que el objetivo era evitar un efecto pesado y monótono poco propio del estilo neoclásico que impera en este escenario.

Además del enlutado de las naves centrales, las capillas y las tribunas fueron adornadas con pabellones sostenidos.

30 Descripción de la decoración realizada en la iglesia de San Isidro para las exequias de Fernando VII, AGP, Sección Histórica, Caja 78, Expediente 7: 1.

31 Descripción de la decoración realizada en la iglesia de San Isidro para las exequias de Fernando VII, AGP, Sección Histórica, Caja 78, Expediente 7: 1-2.
La cornisa principal, la del anillo y la del cuerpo de luces estaban también cubiertas con pabellones enlazados más cortos aportando gran riqueza al conjunto de la decoración. Uno de los elementos que cabe destacar por su retoricismo es la inclusión de atributos alusivos a la función de honras: coronas de laurel, relojes de arena alados y coronas con tibias cruzadas. Estos símbolos, si bien se consideran pobres reminiscencias de épocas anteriores, pretenden manifestar el significado principal de las exequias: el tránsito, la fugacidad de la vida del monarca. ${ }^{32}$

Por último, la capilla mayor fue revestida por un rico pabellón en su arco y, en el interior, se cubrió los resaltos de la barandilla de los órganos y la puerta de la sacristía. Tal como consta en los papeles de Palacio, el retablo mayor fue ocultado bajo un fondo negro y las mesas del altar y los púlpitos adornados con frontales de terciopelo y alfombras. Uno de los púlpitos que ocupaba uno de los machones del arco de entrada al crucero fue extraído antes de las exequias, ya que estorbaba el paso y ocultaba parte del monumento. El único objeto que se dejó que resaltara sobre el sagrario fue «una cruz blanca sostenida por un trozo de columna y agrupada con unos serafines entre nubes». ${ }^{33}$

A partir de aquí se tratará el elemento central sobre el que se asentaban dichos restos y que conformaba la parte más vistosa de las exequias: el túmulo.

\section{EL TÚMULO O CATAFALCO}

El túmulo, también denominado catafalco, pira, mausoleo o monumento, era el elemento principal del aparato funeral. Su naturaleza efímera contrastaba con su simbolismo y suntuosidad y, junto con los jeroglíficos y la decoración, formaba un completo programa iconográfico. La exaltación de la reputación del rey y la monarquía eran valores que debían ser reproducidos a través de estos programas, especialmente si había ciertos desacuerdos en la continuidad dinástica como tras la muerte de Fernando VII.

Como puede verse en el diseño ilustrado por Pharamond Blanchard y recreado posteriormente, ${ }^{34}$ el túmulo dedicado a Fernando VII fue colocado en el centro del crucero de tal manera que era accesible y visible desde cualquiera de las tres naves de la Iglesia. Gracias a la minuciosa descripción de este catafalco, se sabe que por los costados también se podía acceder al túmulo mediante escalinatas perfiladas cuyo ingreso estaba adornado con candelabros «compuestos de un grupo de genios en acción de llorar o lamentarse, ricos paños de terciopelo agrupa sobre otros genios terminando

32 Como señala Mejías Álvarez (2002, 15-16) «Como consecuencia directa del culto y glorificación que el hombre del Renacimiento y Barroco le otorga a la Muerte, las exequias fueron, de todos los festejos reales, las que mayor prestigio y difusión alcanzaron en el Antiguo Régimen».

33 Descripción de la decoración realizada en la iglesia de San Isidro para las exequias de Fernando VII, AGP, Sección Histórica, Caja 78, Expediente 7: 2.

34 Para una mejor comprensión y análisis del túmulo y los elementos decorativos desarrollados para las exequias de Fernando VII se ha recreado dicha arquitectura teniendo en cuenta las dimensiones del interior de la iglesia donde tuvo lugar la celebración y siguiendo minuciosamente las descripciones que se conservan al respecto en el AGP (véase Fig. 4 y 5). La obra ha sido realizada por Víctor García Enguix y la autora. 
FIGURA 3

Diseño del cenotafio y decoración interior de la iglesia de San Isidro el Real para las exequias fúnebres de Fernando VII los días 9 y 10 de mayo de 1834. Pharamond Blanchard (1805-1873)

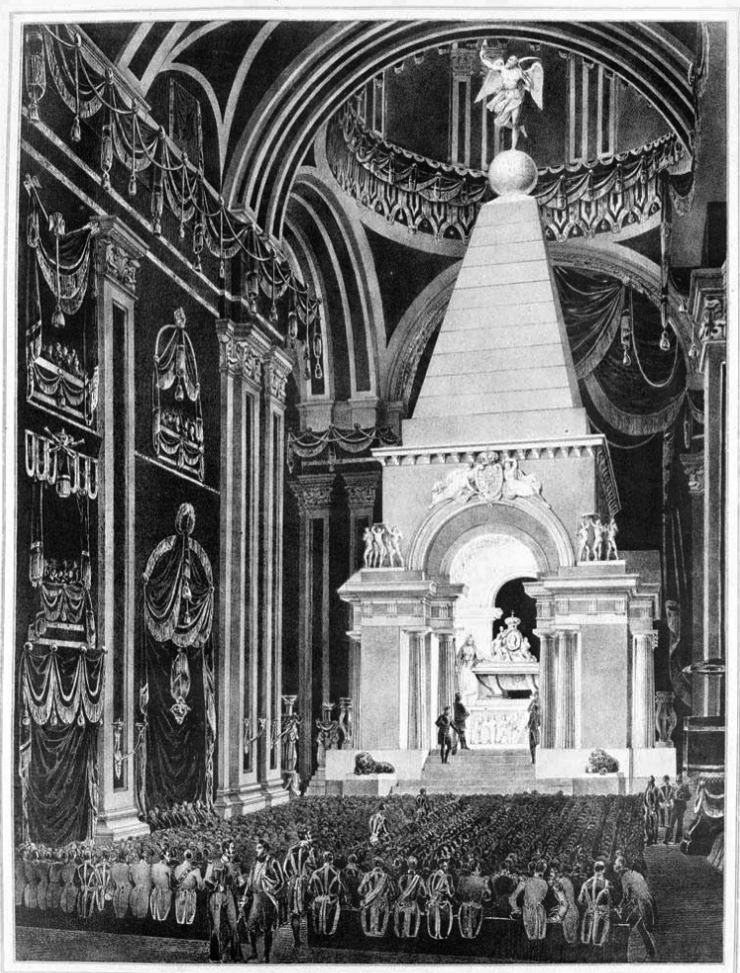

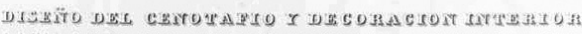

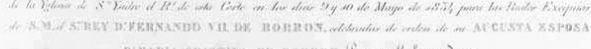

๑ Biblioteca Nacional de España

Fuente: Biblioteca Nacional de España, Madrid (BNE), INVENT/30492. la composición un gran flamero»..$^{35} \mathrm{Su}$ alzado era piramidal, lo que representaba la apoteosis del difunto, y su planta cuadrilonga por ser considerada la más perfecta. ${ }^{36}$

El primero de sus tres cuerpos estaba formado por veinticuatro columnas de orden dórico - cuatro en la fachada y ocho a cada costado- por alegoría a la fortaleza del monarca. Este primer elemento descansaba sobre un zócalo $y$, por el frente, sobre una gran escalinata decorada con dos leones colosales. Este simbólico animal era un atributo de la monarquía borbónica y, en particular, del rey Fernando VII. Además, en las fachadas de los costados y en los macizos de los machones se construyeron dos nichos en los que se veían colgadas las cuatro virtudes cardinales en escultura: la justicia y la fortaleza (esculpidas por José Piquer) y la templanza y la prudencia (compuestas por José Ginés).

FIGURA 4

Interior de la iglesia de San Isidro el Real (Madrid) en la actualidad

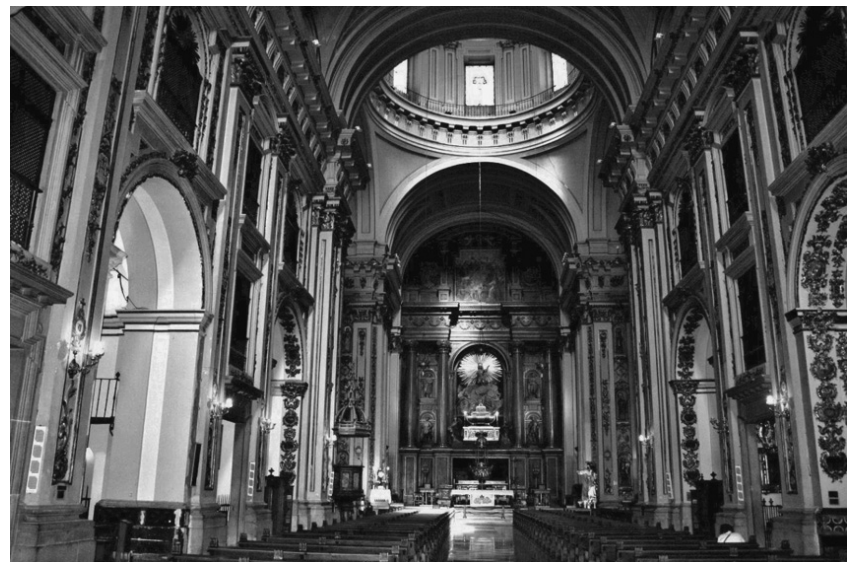

Fuente: fotografía de la autora.

\section{FIGURA 5}

Recreación del túmulo y decoración de la iglesia de San Isidro el Real para las honras fúnebres de Fernando VII los días 9 y 10 de mayo de 1834. Víctor García Enguix y María Ordiñana Gil

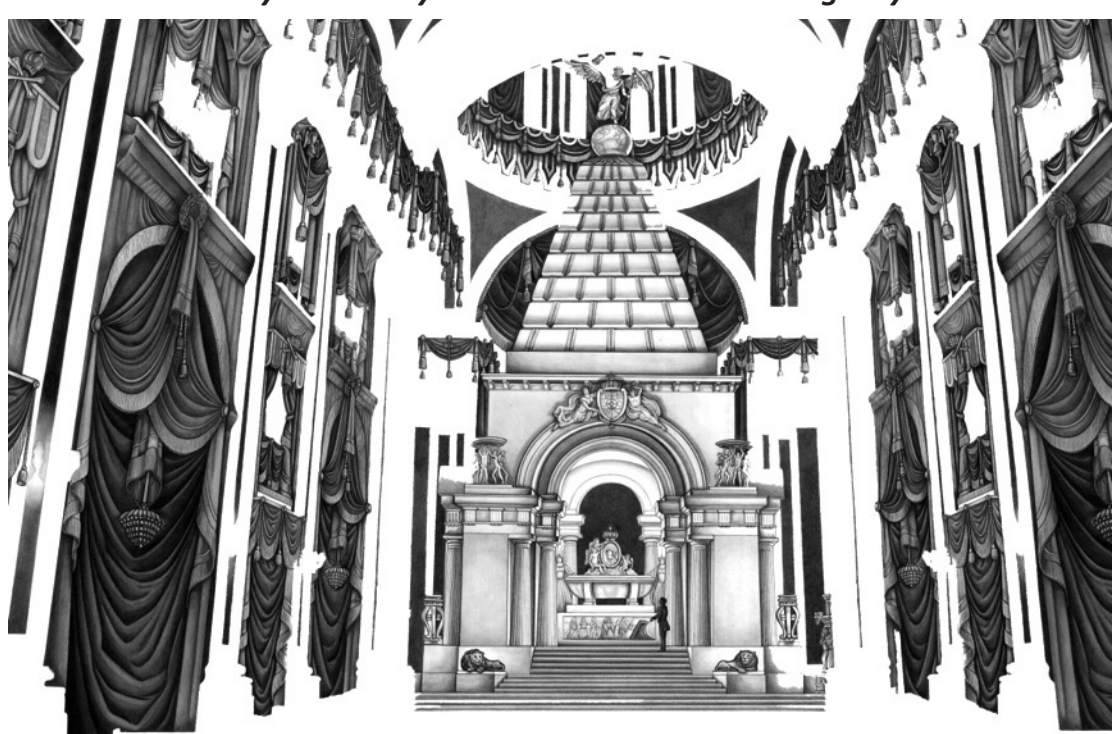

Fuente: elaboración de la autora.

35 Descripción de la decoración realizada en la iglesia de San Isidro para las exequias de Fernando VII, AGP, Sección Histórica, Caja 78, Expediente 7: 3-4.

36 Varela 1990. 
Sobre la cornisa del primer cuerpo se alzaba un segundo cuerpo en forma de ático de planta cuadrada y con arcos en la fachada principal y en la trasera. Por un lado, en la fachada principal se colocó un escudo de armas reales de España sostenido por dos mancebos obra de José Piquer. Por otro lado, sobre el arco trasero se conoce que se ubicó una escultura alegórica: una fama en acción de volar ejecutada por José Ginés. Los planos de los costados también fueron enriquecidos con bajo relieves pintados. Concretamente, el que corresponde al lado de la epístola «representa al Rey dando la paz a la España, y a los pueblos que reviven de manos de ella este beneficio" y, en el lado del evangelio, "se representa al Monarca distribuyendo premios y honores a la virtud y al mérito». ${ }^{37}$ En el interior del monumento se realizó una bóveda esférica, encasetonada y cubierta por un gran anillo. Por último, otro de los elementos que se destaca en esta descripción son los grupos escultóricos de niños colocados en los resaltos de la cornisa los cuales sostienen flameros o vasos.

Sobre este segundo cuerpo se elevaba un tercero que consistía en un zócalo sobre el que se apoyaba una pirámide de "treinta y ocho pies de alta" y construida en piedra berroqueña. En el vértice descansaba un globo terrestre y una estatua de José Tomas que simbolizaba el tiempo con sus atributos y «que en acción de empezar a volar apoya solo un pie en el mundo». ${ }^{38}$

Finalmente, en el centro de este mausoleo se colocó el sarcófago que contenía los restos figurados del monarca. Sobre el zócalo en el que descansa esta pieza se ejecutaron diversos relieves de Leonardo Alenza que, aunque no se distinguen en la litografía de la época, se conoce que tenían alusiones a Fernando VII:

En el plano del que mira al público se ve un bajo relieve pintado que representa al Rey descendiendo al sepulcro, conducido por la muerte, las artes y ciencias se despiden de él y lloran su pérdida. En el colocado en el plano que mira al altar mayor se representa al Rey en acción de desprenderse de las grandezas humanas y apoyarse en la Religión: el tiempo con una Clepsidra parece contar los momentos y las provincias de España a otra parte sumergidas en el desconsuelo. ${ }^{39}$

Además de los bajo relieves, encima del sarcófago se ve un grupo de genios llorando y sustentando una medalla con el busto del Rey. Tocando la urna, a la derecha, se construyó una estatua que representaba la religión y, a la izquierda, otra en representación de España. El diseño del sarcófago del cenotafio corresponde a José Tomás y Geneves.

37 Descripción de la decoración realizada en la iglesia de San Isidro para las exequias de Fernando VII, AGP, Sección Histórica, Caja 78, Expediente 7: 4-5.

38 Descripción de la decoración realizada en la iglesia de San Isidro para las exequias de Fernando VII, AGP, Sección Histórica, Caja 78, Expediente 7: 5.

39 Descripción de la decoración realizada en la iglesia de San Isidro para las exequias de Fernando VII, AGP, Sección Histórica, Caja 78, Expediente 7: 5 .
FIGURA 6

Croquis para el sarcófago del cenotafio erigido en la iglesia de San Isidro para las exequias del rey Fernando VII

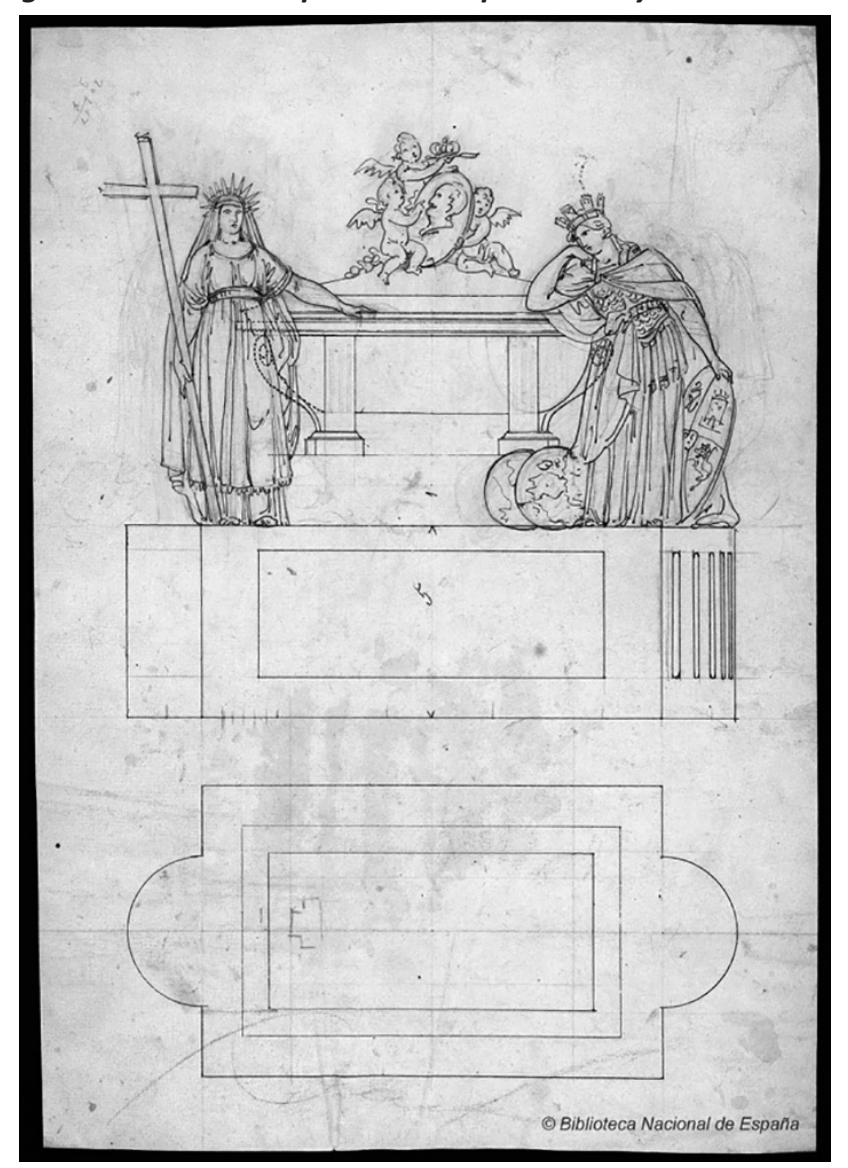

Fuente: Biblioteca Nacional de España, Madrid (BNE), DIB/18/1/4164.

En cuanto a la iluminación, elemento fundamental en todo funeral, estaba dirigida para que la urna funeraria fuese el elemento más brillante. Para tal propósito, se iluminó la parte baja del túmulo con gran número de flameros y se colocó un "aparato» en el interior de la bóveda de la pirámide con varios quinqués.

\section{OFICIO Y MISA DE DIFUNTOS PARA LAS REALES HONRAS FÚNE- BRES DE FERNANDO VII ${ }^{40}$}

Si el fallecimiento de los monarcas favoreció la producción de obras plásticas y literarias, la música no quedó al margen de tal luctuoso escenario. Al igual que los aparatos fúnebres, las composiciones musicales debían reflejar la grandiosidad y solemnidad del culto por la muerte del soberano. De hecho, la música compuesta para exequias reales ha dejado algunos de los ejemplos más elaborados y cautivadores en la historia de la música española como es la conocida Missa pro defunctis de Tomás Luis de Victoria, escrita para las honras fúnebres de María de Austria, la hija del emperador Carlos V (1603). ${ }^{41}$

40 No es objeto de este estudio presentar un análisis pormenorizado de las características musicales de esta obra y su compositor, sino extraer aquellos elementos musicales - y extramusicales- que procuran una comprensión sobre la importancia de la música en el ceremonial de las reales honras de Fernando VII y su adecuación al resto de lenguajes artísticos analizados en apartados anteriores.

41 Véase: Atlas 1998; Ortega Trillo 2012 y Suárez García 2012. 
La composición de la música para las honras regias de Fernando VII fue encargada a Francisco Andreví Castellá, ${ }^{42}$ maestro de la Real Capilla en estos momentos. Su cometido era realizar una obra original siguiendo la tradición compositiva. Así pues, su estructura se dividió en dos partes que correspondían a las del ritual religioso de difuntos que se hacía en dos días: el Oficio de Difuntos para el día 9 de mayo por la tarde y la Misa de Difuntos al día siguiente por la mañana.

Por un lado, el Oficio de Difuntos ${ }^{43}$ fue concebido para 4 solistas, 2 coros, coro de sochantres y gran orquesta y mantuvo la estructura del ritual religioso con sus correspondientes alternancias de canto llano:

FIGURA 7

Estructura del Oficio de Difuntos de Francisco Andreví Castellá (1834)

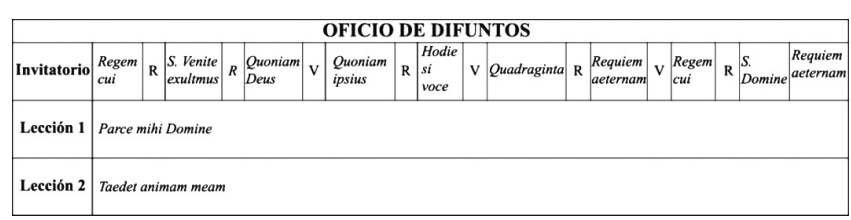

Fuente: elaboración de la autora.

\section{FIGURA 8}

Intervenciones de canto Ilano en el Oficio de Difuntos $\mathrm{R}$.

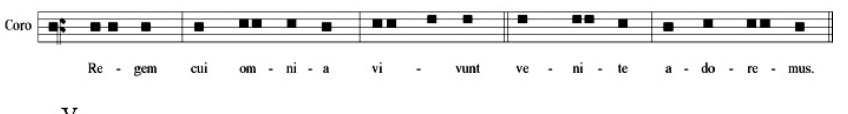

v.

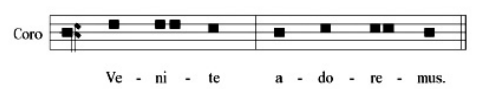

Fuente: elaboración propia a partir de: Oficio de Difuntos de Francisco Andreví Castellá (1834), AGP, Sección Real Capilla, Caja 610, Expediente 31.

Por otro, la Misa de Difuntos, ${ }^{44}$ con la misma plantilla orquestal, también siguió la estructura musical usual con la sustitución del Benedictus por un Motete: ${ }^{45}$

42 Francisco Andreví Castellá (Sanaüja 1786- Barcelona 1853) es una de las figuras con un repertorio más prolífico y difundido que se sitúa en un contexto de crisis de la música española marcada por las circunstancias políticas del momento (Casares Rodicio 1995). Fue maestro de capilla de las catedrales más relevantes del momento y recorrió instituciones de prestigio, algunas de cuales fueron enclaves para la introducción de las corrientes adscritas al Clasicismo. Destacan de forma considerable: Catedrales de Segorbe (1808-1814), Santa María del Mar de Barcelona (1814-1819), Valencia (1819-1829), Burdeos (ca.1839-1845) y la Real Capilla de Madrid (1830-1836), en cuyas oposiciones cabe destacar su triunfo en dura competencia con músicos reconocidos por la Musicología Española como Indalecio Soriano (padre de Mariano Soriano Fuertes), Hilarión Eslava, Ramón Carnicer y Antonio Ibáñez (Ordiñana Gil 2016).

43 Oficio de Difuntos de Francisco Andreví Castellá (1834), AGP, Sección Real Capilla, Caja 610, Expediente 31.

44 Misa de Difuntos de Francisco Andreví Castellá (1834), AGP, Sección Real Capilla, Caja 617, Expediente 42.

45 En la estructura del Oficio y Misa de Difuntos se observa la ausencia de un responso tal y como era habitual en la tradición litúrgica y como aparece en todas las obras similares de esta época. Por ello, se presume que el responso Libera me Domine, también conservado en el Archivo General de Palacio, pertenece a esta obra y que se interpretaría al final de la Misa u Oficio.

\section{FIGURA 9}

Estructura de la Misa de Difuntos de Francisco Andreví Castellá (1834)

\begin{tabular}{|c|c|c|c|}
\hline \multicolumn{4}{|c|}{ MISA DE DIFUNTOS } \\
\hline Introducción & Requiem aeternam & S. Te decet & Requiem aeternam \\
\hline \multicolumn{4}{|l|}{ Kyrie } \\
\hline Secuencia & \multicolumn{3}{|l|}{ Dies irae } \\
\hline Ofertorio & A. Domine Jesu & \multicolumn{2}{|c|}{ v. Hostias et preces } \\
\hline \multicolumn{4}{|l|}{ Sanctus } \\
\hline Motete & \multicolumn{3}{|c|}{ Peccantem me quotidie } \\
\hline \multicolumn{4}{|l|}{ Agnus Dei } \\
\hline Postcommunio & A. Lux aeterna & \multicolumn{2}{|c|}{ v. Requiem aeternam } \\
\hline Responso & \multicolumn{3}{|c|}{ R. Libera me Domine } \\
\hline
\end{tabular}

R. Responso A. Antífona S. Salmo v. Verso. Fuente: elaboración de la autora.

Además de la composición de ambas partes, Andreví tenía la obligación de organizar su ejecución conforme a la etiqueta en uso. Según consta, el maestro terminó la obra en febrero de 1834 (menos de 5 meses después de la noticia de la muerte del monarca), y a partir de ese momento, se hizo cargo de la organización de la interpretación con todo lo que requería en cuanto a número de intérpretes, presupuestos y diligencias previas. En los días anteriores a la ejecución de las exequias, Andreví solicitó al Patriarca de las Indias:

Estando próximas a celebrarse la honras de nuestro Augusto Soberano el S[eño]r D[o]n Fernando 7이ue] e[stá] e[n] g[loria]), y habiéndome hecho presente el primer sochantre la necesidad que se aumenten las voces del coro de cato llano, pues de lo contrario desdeciría con el lleno los de la orquesta; me veo en la precisión de ponerlo en el superior conocimiento de V[uestra] E[xcelencia] para la determinación que estime oportuna pareciéndome justa la advertencia, y considerando que con seis voces de aumento, se habrá logrado el objeto, añadiendo que así se ha verificado, en las honras de la Reina D[oñ]a Mar[í]a Josefa Amalia. ${ }^{46}$

La reina regente aprobó las peticiones del compositor sin ningún inconveniente. Como puede leerse, Andreví tenía como referencia la ejecución de las últimas exequias que habían tenido lugar en la corte, a saber: las de la reina y tercera esposa de Fernando VII, María Josefa Amalia de Sajonia. Si bien estas tuvieron lugar antes de la llegada del maestro a la corte (1829), Andreví tuvo muy presente su organización y presupuesto para la Real Capilla. ${ }^{47}$ Tan solo unos días antes de la función de exequias, el 2 de mayo, el Patriarca comunicaba a Andreví:

Mediante la necesidad de que se aumenten las voces de canto llano para la mayor solemnidad en las honras q[u]e han de celebrarse por el alma del S[eño]r Rey D[o]n Fernando Séptimo (q[ue] e[stá] e[n] g[loria]) como U[sted] expresa en su oficio de 25 de abril último, podrá verificarlo hasta el número de seis voces más de aquella clase, según propone. Lo que servirá a U[sted] de gobierno, y en contestación a su citado oficio. ${ }^{48}$

46 Oficios de la Real Capilla de 1757 a 1835, Biblioteca Nacional de España, Madrid (BNE), MSS/14091/168/413.

47 Según la documentación conservada en la Biblioteca Nacional de España (MSS/14073/12) el presupuesto destinado para la contratación de intérpretes en las exequias oficiales de María Josefa Amalia de Sajonia fue de 18.680 reales de vellón.

48 Oficios de la Real Capilla de 1757 a 1835, BNE, MSS/14091/ $169 / 414$. 
Las voces de canto llano no fueron las únicas contrataciones para las exequias de Fernando VII. De acuerdo con la cuenta de gastos presentada al Patriarca de las Indias, para la interpretación del Oficio y Misa de Difuntos el maestro consideró oportuno contratar hasta 70 músicos externos (25 voces, 39 instrumentistas y 6 salmistas). El gasto final de la partida por los contratos alcanzó los 17.498 reales de vellón, una suma elevada que se añadiría al resto de los gastos del ceremonial. ${ }^{49}$

TABLA 1

Tablas correspondientes a la plantilla de la Real Capilla según nóminas de febrero de 1834 y relación de intérpretes contratados para las exequias de Fernando VII los días 9 y 10 de mayo de 1834

\begin{tabular}{|c|c|c|c|}
\hline & $\begin{array}{c}\text { Intérpretes } \\
\text { de la Real Capilla } \\
\text { según nóminas } \\
\text { de febrero de } 1834\end{array}$ & $\begin{array}{c}\text { Intérpretes } \\
\text { contratados } \\
\text { para las exequias } \\
\text { de Fernando VII }\end{array}$ & Totales \\
\hline Capellanes de Altar & 9 & & 9 \\
\hline Sochantres & 2 & & 2 \\
\hline Salmistas & 7 & 6 & 13 \\
\hline Oboes y Flautas & 2 & 2 & 4 \\
\hline Corno inglés & & 1 & 1 \\
\hline Clarinetes & 2 & 3 & 5 \\
\hline Fagotes & 1 & 1 & 2 \\
\hline Trompas y Clarines & 3 & 5 & 8 \\
\hline Bucsen & & 2 & 2 \\
\hline Ofigles & & 2 & 2 \\
\hline Timbales & & 1 & 1 \\
\hline Tiples & 2 & 5 & 7 \\
\hline Contraltos & 3 & 6 & 9 \\
\hline Tenores & 3 & 6 & 9 \\
\hline Bajos & 3 & 8 & 11 \\
\hline Bajones & 2 & 1 & 3 \\
\hline Violines & 10 & 13 & 23 \\
\hline Violas & 2 & 3 & 5 \\
\hline Violonchelos & 2 & 2 & 4 \\
\hline Contrabajos & 2 & 3 & 5 \\
\hline Total & 55 & 70 & 125 \\
\hline
\end{tabular}

Fuente: elaboración de la autora.

A estos intérpretes cabría sumarles los miembros de la Real Capilla que según nóminas de febrero de 1834 serían unos 55 músicos, excluyendo puestos auxiliares tales como apuntador, etc. ${ }^{50}$

En suma, intervendrían un total aproximado de 125 músicos, una gran orquesta y coro de voces que sin duda evidencia el interés del maestro de capilla por dotar a la ceremonia de un carácter grandioso.

La colocación de la gran orquesta y coros para la función de honras fue a los pies de la iglesia y separados por gradas,

49 Cuenta del maestro de capilla de los gastos ordinarios del primer trimestre de 1834, incluyendo los extraordinarios por las honras de Fernando VII, AGP, Sección Histórica, Caja 78, Expediente 7.

50 Nóminas de la Real Capilla de febrero de 1834, AGP, Sección Real Capilla, legajo 1132; Cuenta del maestro de capilla de los gastos ordinarios del primer trimestre de 1834, incluyendo los extraordinarios por las honras de Fernando VII, AGP, Sección Histórica, Caja 78, Expediente 7. tal como evidencia el esquema trazado ${ }^{51}$ supuestamente por el propio Andreví conservado en la Biblioteca Nacional de España. ${ }^{52}$ Siguiendo dicho esquema, a nivel del suelo se situarían los coros, junto con los bajones, un contrabajo y un violonchelo o violón; en la primera grada se encontraría la sección de cuerda (violines principales y segundos, violones y contrabajos) que se completaría con las violas, 2 violines segundos, 1 violón y 2 contrabajos de la segunda grada; además, en este segundo nivel se localizarían las maderas (menos el clarinete) y las trompas primeras; por último, la tercera grada se reservaría para clarinetes, clarines, ofigles, ${ }^{53}$ trompas, bucsens ${ }^{54}$ y timbales.

\section{FIGURA 10}

Esquema de la plantilla orquestal trazado supuestamente por Francisco Andreví para las honras del rey Fernando VII los días 9 y 10 de mayo de 1834

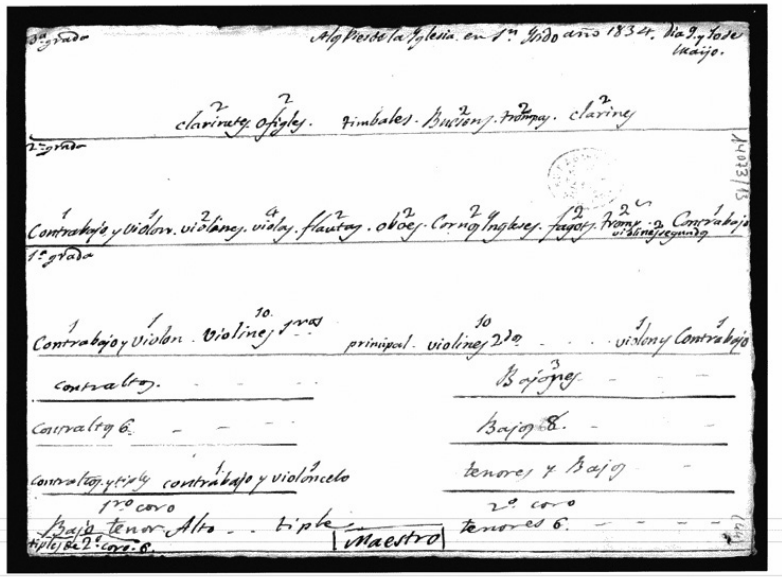

Fuente: Biblioteca Nacional de España, Madrid (BNE), MSS/14073/13/44.

\section{FIGURA 11}

Reproducción del esquema de la plantilla orquestal de Francisco Andreví para las honras del rey Fernando VII los días 9 y 10 de mayo de 1834

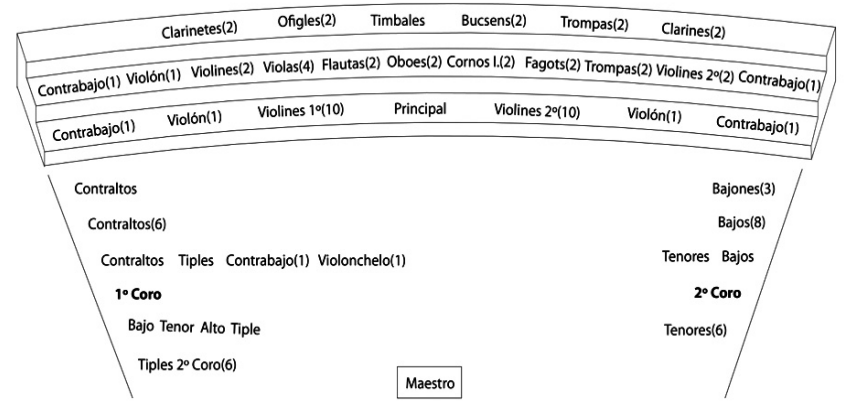

Fuente: elaboración de la autora a partir del original.

51 Hay indicios en la grafía que muestran que podría tratarse de un documento autógrafo del compositor.

52 Papeles referentes a la Capilla Real en tiempos del Maestro Francisco Andreví, BNE, MSS/14073/13/44.

53 El ofigle (oficleide o figle) es un instrumento de viento metal que pertenece a la familia de la corneta con llave (Ordiñana Gil 2016).

54 El bucsen (buccin, buccèn o bucken) es un instrumento de viento metal de la familia de los trombones de varas con pabellón de dragón o serpiente y relacionado con la búsqueda de sonoridades extremas (Ordiñana Gil 2016). 
Respecto a las características musicales, a grandes rasgos, puede decirse que Andreví siguió los preceptos del estilo clásico con melodías variadas de corte belcantista, al mismo tiempo que incorporó recursos armónicos y dinámicos propios del Romaticismo. Su carácter es claramente luctuoso con el empleo del cromatismo, una tímbrica obscura y la máxima del contraste (en dinámicas, timbres, texturas y/o tempos). Este último recurso estaría en clara coherencia con la decoración de la iglesia en la búsqueda del contraste entre el blanco y el negro.

Todos los elementos musicales (sonido, armonía, melodía y ritmo) participan en el tratamiento expresivo del discurso literario y, de hecho, se han localizado fragmentos en los que se realiza una adecuación del discurso musical al literario. Un ejemplo musical que cabe destacar es el pasaje Tuba mirum de la Secuencia de la Misa. En este, los instrumentos de viento metal (los bucsens, junto con las trompas, ofigle y clarines) inician un nuevo tema describiendo el significado del texto (las trompetas) al estilo de una fanfarria, es decir, con toques largos y repetitivos con claros fines ceremoniales hacia la realeza. Además de estos fragmentos puntuales, a lo largo del Oficio y Misa se lleva a cabo un tratamiento retórico ${ }^{55}$ en algunas palabras clave como inferno (infierno), erubescant (vergüenza) o turbatus (turbios). El empleo de este tipo de recursos permite entrever la correlación de significados entre las distintas manifestaciones artísticas. El objetivo es el mismo, esto es: la búsqueda de un dramatismo que transmita el dolor por la pérdida y resalte los valores de la monarquía borbónica y, en particular, de Fernando VII.

\section{CONCLUSIONES}

A lo largo de este artículo queda patente el papel necesario y obligatorio que cumplía la música en las ceremonias de exequias reales $u$ honras fúnebres. Esta conformaba el elemento integrador de las artes y estaba compuesta expresamente para un personaje regio. Se trata pues de uno de los géneros más importantes a considerar en el repertorio musical del Palacio Real de Madrid, así como en la historia de la institución y sus personajes.

Las exequias reales de Fernando VII siguieron manteniendo la relevancia de épocas anteriores con la construcción de un aparato funeral, la recitación de sermones panegíricos y la composición e interpretación de un oficio y misa de difuntos. El ceremonial, que tuvo lugar los días 9 y 10 de mayo de 1834 en la iglesia San Isidro el Real (Madrid), conservó la etiqueta funeraria al mismo tiempo que adoptó las nuevas exigencias de apertura al público. El aparato funeral, si bien sufrió una simplificación en los símbolos, siguió cumpliendo su función simbólica a través de los elementos arquitectónicos, los temas y el empleo de la luz. La fugacidad de la vida, la fortaleza y los atributos propios de la monarquía borbónica, y en particular de Fernando VII, son algunos de los temas característicos de este monumento. La música, concentrada en gran medida en el Oficio y Misa de Difuntos de Francisco Andreví Castellá, conservó la estructura del

55 En este punto no se ha considerado adecuada la aplicación de la terminología del arte retórico (figuras retóricas) del Barroco por tratarse de un uso descontextualizado. ritual religioso de difuntos y mostró una coherencia con el discurso marcado para este acto. El empleo de una tímbrica obscura, las técnicas contrastantes y el tratamiento expresivo del texto procuraron unos significados análogos a los temas y tópicos del aparato funeral. La concepción y ejecución de esta obra para gran orquesta y coros pone así de manifiesto el grado de importancia que la monarquía hispánica otorgaba a la música en estas ceremonias, así como la condición y aptitudes de su maestro Andreví.

Con todo, a pesar de las graves circunstancias políticas y económicas tras la muerte de Fernando VII, sus honras fúnebres reflejaron la magnificencia en el culto propia de la tradición. El Oficio y Misa de Difuntos de Andreví es una obra de grandes dimensiones la cual no hubiera sido posible sin la voluntad de Fernando VII por mejorar las dotaciones y estructuras de la Real Capilla durante su reinado. La minuciosidad en los detalles, como la colocación de los intérpretes o el empeño en la selección de las voces, evidencia la magnitud de este ceremonial y el grado de compromiso que adquirieron sus organizadores.

\section{BibLIOgRAFÍA}

Allo Manero, María Adelaida y Juan Francisco Esteban Lorente. 2004. «El estudio de las exequias reales de la monarquía hispana: siglos XVI, XVII y XVIII». Artigrama 19: 39-94.

Atlas, Allan. W. 1998. Renaissance Music: Music in western Europe, 1400-1600. New York: W. W. Norton \& Company.

Azanza López, José Javier. 2000. «Túmulos y jeroglíficos en Pamplona por la muerte de Isabel de Farnesio». Archivo Español de Arte 73 (289): 45-61. https://doi.org/10.3989/aearte.2000.v73.i289.805

Azcárate Ristori, José María de. 1962. "Datos sobre túmulos de la época de Felipe IV». Boletín del Seminario de Estudios de Arte y Arqueología 28: 289-296.

Berlin, Heinrich y Jorge Luján Muñoz. 1983. Los túmulos funerarios en Guatemala. Guatemala: Academia de Geografía e Historia de Guatemala.

Bonet Correa, Antonio. 1960. "Túmulos del Emperador Carlos V». Archivo Español de Arte 33 (129): 55-66.

Bonet Correa, Antonio. 1961. «El túmulo de Felipe IV de Herrera Barnuevo y los retablos-baldaquinos del barroco español». Archivo Español de Arte 34 (136): 285-296.

Bottineau, Yves. 1968. «Arquitecture éphémère et baroque espagnol». Gazette des Beaux-arts 2: 213-230.

Campos y Fernández de Sevilla, Javier. 2001. «Exequias en honor de Felipe III celebradas en Lima en 1621». Hispania Sacra 53: 327344. https://doi.org/10.3989/hs.2001.v53.i107.237

Candel Crespo, Francisco. 1994. "Tres obispos albacetenses en la España de Fernando VII». Al-Basit: Revista de estudios albacetenses 35: 113-132.

Capdepón Verdú, Paulino. 1999. "Soler y Ramos, Antonio». En Diccionario de la Música Española e Hispanoamericana, edición coordinada por Emilio Casares Rodicio, vol. IX, 1128-1132. Madrid: SGAE.

Casares Rodicio, Emilio. 1995. «La Música del siglo XIX español. Conceptos fundamentales». En La Música Española en el siglo XIX, edición de Emilio Casares Rodicio y Celsa Alonso González, 13-122. Oviedo: Universidad de Oviedo.

Flores Rodrigo, Susana. 2005. "La música en las exequias reales de la ciudad de Barbastro en el siglo XVII». En Música y cultura urbana en la edad moderna, edición coordinada por Andrea Bombi, Juan José Carreras López y Miguel Ángel Marín López, 295-305. Valencia: Universidad de Valencia.

Fuente Charfolé, José Luis de la. 2013. "La intervención musical en las exequias reales de la Catedral de Cuenca (1598-1621)». Hispania Sacra 131: 103-138. https://doi.org/10.3989/hs.2013.004 
Garrido, Tomás, ed. 1998. Mariano Rodríguez de Ledesma. Oficio y Misa de Difuntos. Madrid: Instituto Complutense de Ciencias Musicales.

Garrido, Tomás y Álvaro Zaldívar Gracia. 2008. [CD-ROM]. Mariano Rodríguez de Ledesma. Oficio y Misa de Difuntos. Zaragoza: Las Tres Sorores.

Gil Tárrega José Ramón, dir. 2001. [CD-ROM]. Días de gloria y muerte. Dos misas de José de Torres (1670-1738). Madrid: Sociedad Española de Musicología.

González Marín, Luis Antonio, ed. 2004a. José de Nebra. Oficio y Misa de Difuntos: para las reales honras de la reina nuestra señora Doña Maria Barbara de Portugal, que goza de Dios (1758). Madrid: Instituto Complutense de Ciencias Musicales.

González Marín, Luis Antonio, ed. 2004b. Música para exequias en tiempo de Felipe IV. Barcelona: Institución Milà i Fontanals.

Iglesias, Alejandro Luis. 1989. En torno al barroco musical español: el Oficio y la Misa de difuntos de Juan García de Salazar. Salamanca: Universidad de Salamanca y Colegio Universitario de Zamora.

Lolo, Begoña. 1995. «La música en la Real Capilla después de la Guerra de la Independencia. Breve esbozo del reinado de Fernando VII». Cuadernos de Arte de la Universidad de Granada 36: 157-169.

Lolo, Begoña. 2000. Días de gloria y muerte. Misas de José de Torres en honor del rey Luis I. Palacio Real, Madrid, 1724. Madrid: Sociedad Española de Musicología.

Maza, Francisco de la. 1946. Las piras funerarias en la historia y en el arte de México. México: Anales del Instituto de Investigaciones Estéticas.

Mejías Álvarez, María Jesús. 2002. Fiesta y muerte regia. Las estampas de túmulos reales del AGI. Sevilla: Consejo Superior de Investigaciones Científicas.

Morales Folguera, José Miguel. 1988. «Los túmulos funerarios de Carlos III y la imagen del Rey en Hispanoamérica y Filipinas». Boletín de arte 9: 135-158.
Ordiñana Gil, María. 2016. Oficio y Misa de Difuntos de Francisco Andreví Castellá (1786-1853) en el contexto de las exequias reales españolas del siglo XIX. Tesis Doctoral. Universidad Católica de Valencia "San Vicente Mártir».

Ortega Trillo, Jafet Ramón. 2012. «Canto Llano y polifonía en el Officium Defunctorum de Tomás Luis de Victoria: Interacciones e interpretación». Revista de Musicología 35 (1): 317-333.

Ramos Sosa, Rafael. 1992. Arte festivo en Lima virreinal: siglos XVIXVII. Sevilla: Consejería de Cultura y Medio Ambiente - Asesoría Quinto Centenario, D.L.

Robledo Estaire, Luis. 1999. «Capilla Real». En Diccionario de la Música Española e Hispanoamericana, edición coordinada por Emilio Casares Rodicio, vol. III, 119-132. Madrid: SGAE.

Rodríguez Moya, Inmaculada y Victor Mínguez Cornelles. 2012. "Cultura simbólica y fiestas borbónicas en Nueva Granada. De las exequias de Luis I (1724) a la proclamación de Fernando VII (1808)». Revista CS 9: 115-143.

Soto Caba, Victoria. 1988. "Teatro y Ceremonia: algunos apuntes sobre las exequias barrocas». Revista de la Facultad de Geografía e Historia 2: 111-138.

Suárez García, José Ignacio. 2012. «El embellecimiento retórico en el Officium Defunctorum de Tomás de Victoria». Revista de Musicología 35 (1): 263-294.

Varela, Javier. 1990. La muerte del Rey, el ceremonial funerario regio de la monarquía española (1500-1885). Madrid: Turner Libros.

Virgili Blanquet, María Antonia. 1995. «La Música religiosa en el siglo XIX español». En La Música Española en el siglo XIX, edición de Emilio Casares Rodicio y Celsa Alonso González, 375-405. Oviedo: Universidad de Oviedo.

Virgili Blanquet, María Antonia. 2004. "La música religiosa en el siglo XIX español». Revista Catalana de Musicología 2: 181-202. 